\title{
The skeletal and heaped characteristic of traditional masonry structures
}

\author{
E. F. Alioglu ${ }^{1} \&$ B. Alper ${ }^{2}$ \\ ${ }^{I}$ Graduate Program in the Preservation of Cultural Heritage, \\ Kadir Has University, Turkey \\ ${ }^{2}$ Faculty of Architecture, Department of History of Architecture, \\ Yildiz Technical University, Turkey
}

\begin{abstract}
Just as in all pre-industrial societies, the historic structures in Anatolia derive from two materials, timber and stone. In timber construction, two categories, namely heaped construction and skeletal construction, are clearly distinguishable. In research to date, it can be seen that these categories have been clearly defined and explained. Yet, structural definitions in masonry buildings are mostly limited to the term heaped construction. However, in traditional masonry structures, it is possible to see, whether clearly or under a layer, a construction that reminds one of skeletal construction.

In this paper, historical masonry structures that have been often described as heaped construction, but which actually contain both heaped and skeletal system characteristics, will be discussed. This dual-system will be examined with examples from Ottoman mosques and masonry houses in Anatolia.
\end{abstract}

Keywords: skeletal construction, heaped construction, Ottoman mosques, masonry houses.

\section{Introduction}

Traditional masonry structures are generally discussed in two parts; the load bearing components and the super structure. The sub-categories of load bearing components are the singular and continuous load bearers and those of the super structure are straight and curvilinear roof layers.

Continuous load bearers are walls made of materials such as stone, brick or the alternating combination of these two, which have a load bearing quality. 
These materials transfer the load deriving from their own weight and the super structure, to the foundation. The totality of the walls here are capable of acting as a load bearer no matter where the load originates from. For this reason, the placement, size and number of openings in the wall such as passages, doors and windows is important. This is because any unconventional opening will diminish the load bearing quality of the wall. Buildings constructed with continuous load bearers are also named heaped constructions. This heaped construction is achieved by the stacking of stone or brick on top of each other, for binding using mortar and cramps and reinforcing bars.

Singular load bearers are elements such as pillars and columns constructed at the point where the load from the horizontal elements of the construction and that of the super structure is concentrated. The pillars, as are the walls, are constructed of stone, brick, or the alternating combination of these two, placed one on top of the other. The columns are either monolithic or segmental. Spaces in which singular load bearers are most common are defined with terms such as revaqs, colonnades and spaces with multi pillars. Yet there is no definition that stresses the technical characteristic of the load bearing system of the building. However, this is a system which has been constructed of singular load bearers with a technique that can be called "skeletal construction". When continuous and singular load bearers coexist in traditional masonry structures, the definition is, once more, heaped construction.

A significant criterion that determines the system of heaped and skeletal construction is the structural aspect of the super structure. Straight and curvilinear super structures have been used in both heaped and skeletal construction systems. In these cases, the technical characteristic of the relationship between the super structure and the underlying structure has given way to heaped or skeletal construction system. For example, the dome on squinches can only stand on load bearing walls, whereas a pendentive dome can be erected on columns or pillars.

\section{Examples}

The skeletal character of the masonry heaped structure comes into view in several examples. Skeletal design in heaped structure buildings may be required at certain points for various reasons. This necessity may often originate from the function of the building. In some cases need for creating semi open spaces and in some others need for large areas, urges the skeletal character to be utilized in masonry construction.

The need for open spaces incorporated revaq systems whatever function they may serve for, into the design around courtyards, or on the facades of buildings. Typical revaq examples can be seen at the late comer's porch, the entrance spaces of public buildings, such as imaret (soup kitchen), library, the courtyards of madrasa, Han and houses or at the street facades of buildings (Figure 1).

In such examples the masonry walls are often load bearers. However the semi open space requirement of the design incorporated single load bearers such as columns and pillars. The relationship between semi open spaces showing 


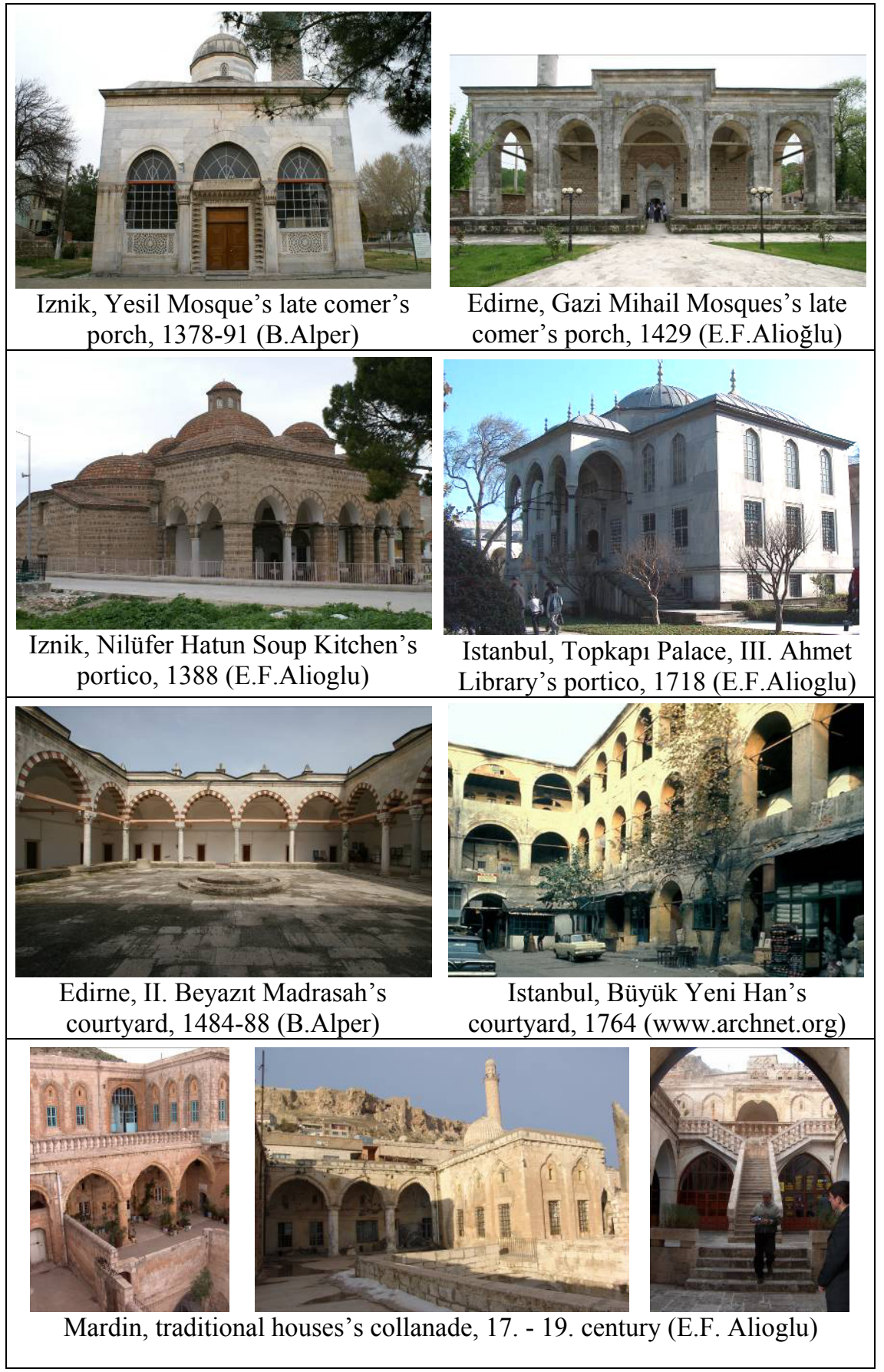

Figure 1: Semi-open spaces with masonry skeletal structure character. 
masonry skeletal characteristic with masonry walls seem like continuous load bearers, involve engineering computations which should be investigated. The load of the dome covering each bay is transferred to the supports through main arches.

Here two structural system approaches confronting each other coexist. When transferring the load originating from the super structure to the massive walls through squinches or pendentives, the stability of structural system is achieved by increasing the wall thickness. However when the load of the super structure is transferred to the supports through main arches or pendentives, at the point of support the columns or pillars are designed accordingly in form and section, in order to transfer the load to the ground [1]. Engineering analysis of buildings where two different structural systems coexist is crucial. These analyses will bring to light whether or not massive seeming structures in mixed systems, carry skeletal structural characteristics.

The requirement for closed and large areas created skeletal structure in masonry construction. The religious and commercial buildings ought to shelter large public groups or buildings that have severe public or merchandize traffic incorporated masonry skeletal structures. The mosques, covered bazaars of the Ottoman architecture can be given as examples (Figure 2). The large spaces used as depots and stables in houses of merchants also show masonry skeletal structure [2] (Figure 3).

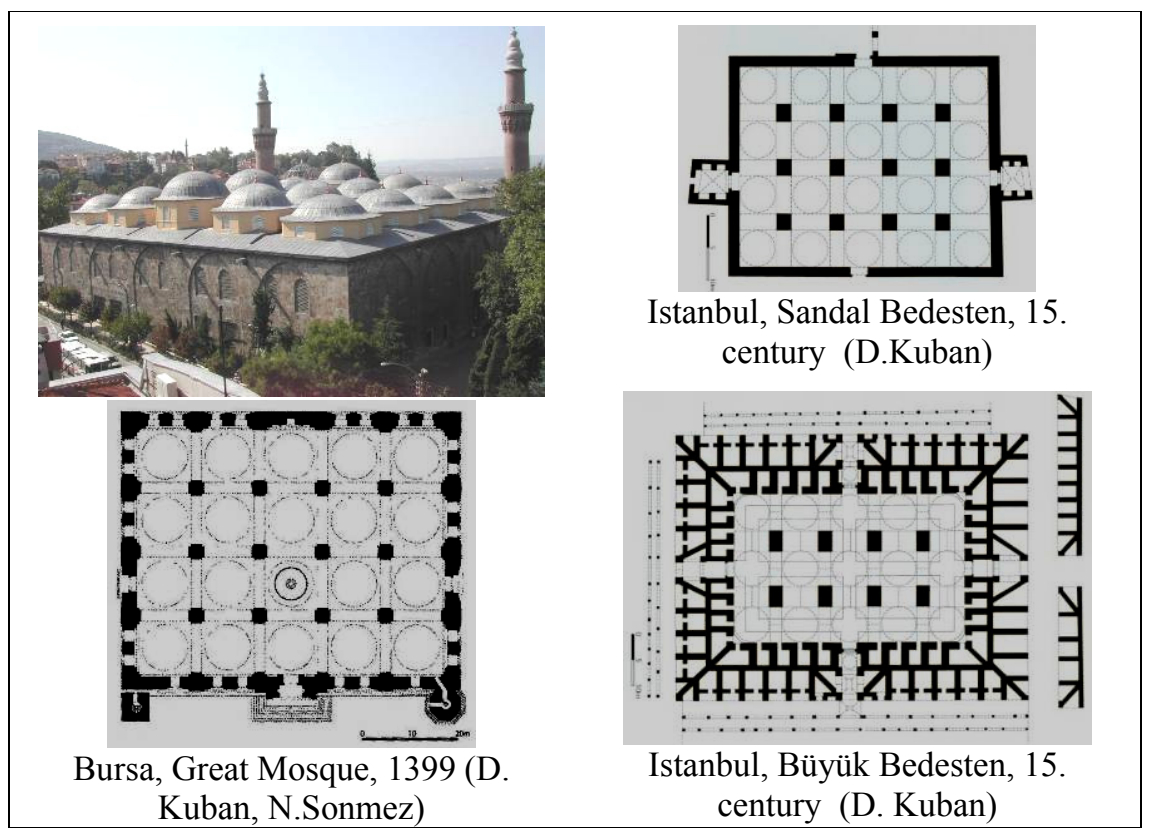

Figure 2: $\quad$ Multi-pillared covered spaces. 


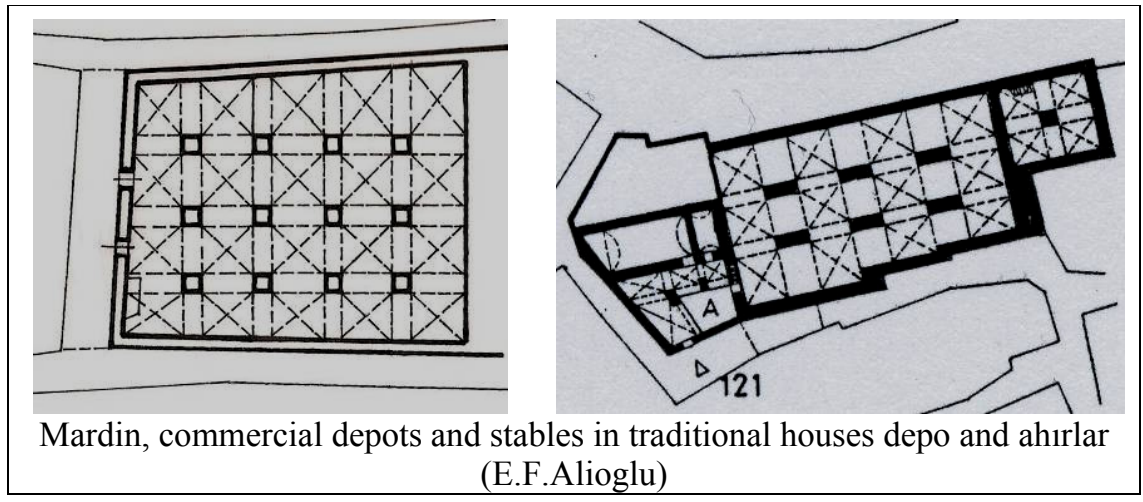

Figure 3: $\quad$ Multi-pillared covered spaces.

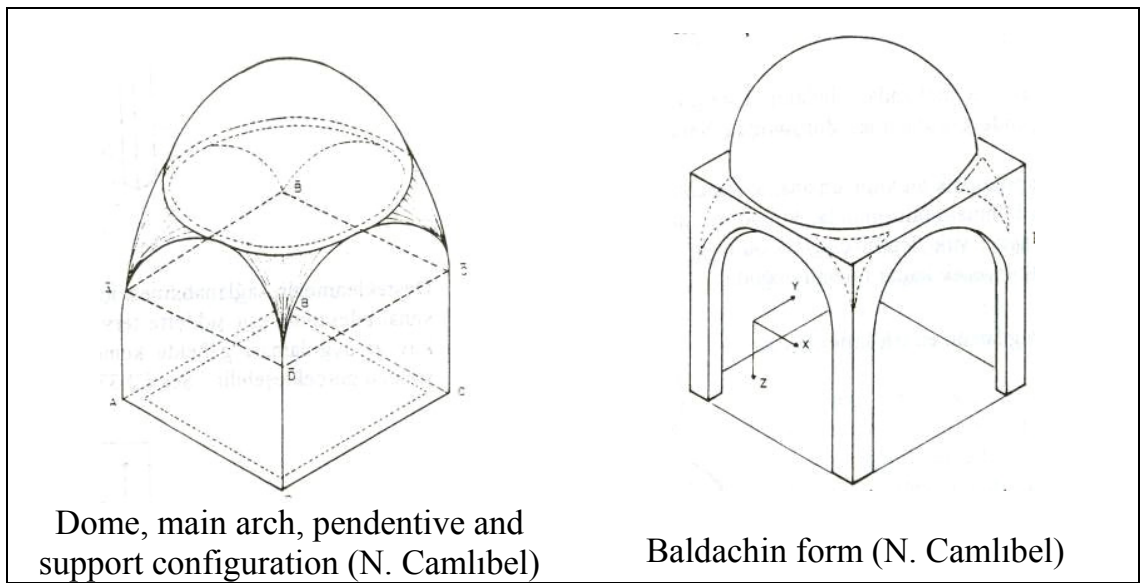

Figure 4: Baldachin form.

The single bay unit defines the multi pillared large spaces. This unit is often come into light in the history of architecture, especially in Ottoman architecture defined as the baldachin or the chartaq [3]. Baldachin is the form transferring the load of the dome covering the square area through main arches to four pillars or columns. A baldachin is formed by elements of dome, main arches, pendentives, pillars or columns. The dome is the super structure which has approximately a semi sphere form. One of the elements that deliver the load of the dome to the corners is main arch and the other is pendentive. The main arch delivers the load of the super structure from the sides to the corners, whereas the pendentive is a transition element delivering the same load directly to the pillars. Pillars or columns are individual vertical structural elements. By looking at the elements that constitute the baldachin, the skeletal structure definition is easily derivable, because the load of the super structure is transferred not to continuous structures 
like walls, but instead to singular vertical structures like pillars or columns (Figure 4).

The simplest form of baldachin is tombs. The skeletal structure character of baldachin is evident especially in open tombs. The sub-categories of open tombs also display a similar character (Figure 5).

The baldachin dominated the construction technology of the Ottoman architecture starting from early on especially of the mosque architecture. So much that, The Classical Ottoman Architecture synonym of the mosque architecture of the architect Sinan, carries variations of baldachin. Sinan took advantage of the structural aspect of baldachin in his designs. These advantages were displayed in plan, section and elevations in Sinan's designs. Primarily the central space organization was formulated in numerous examples [4]. The central baldachins were placed sometimes within a square, sometimes in a rectangle diversifying from the lateral spaces in dimension (Figures 6-8).

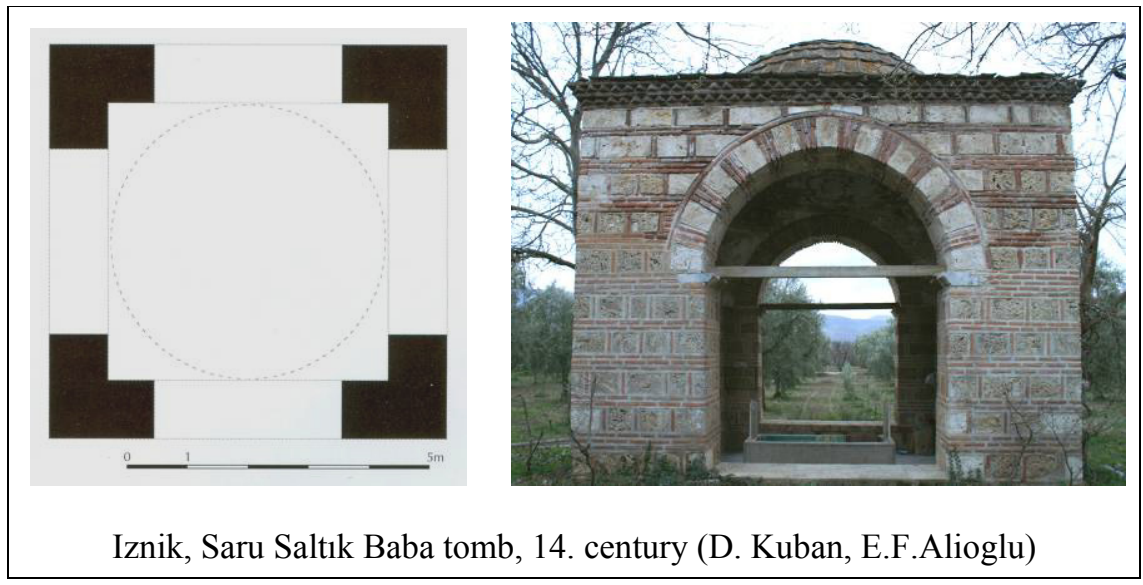

Figure 5: Baldachin form.

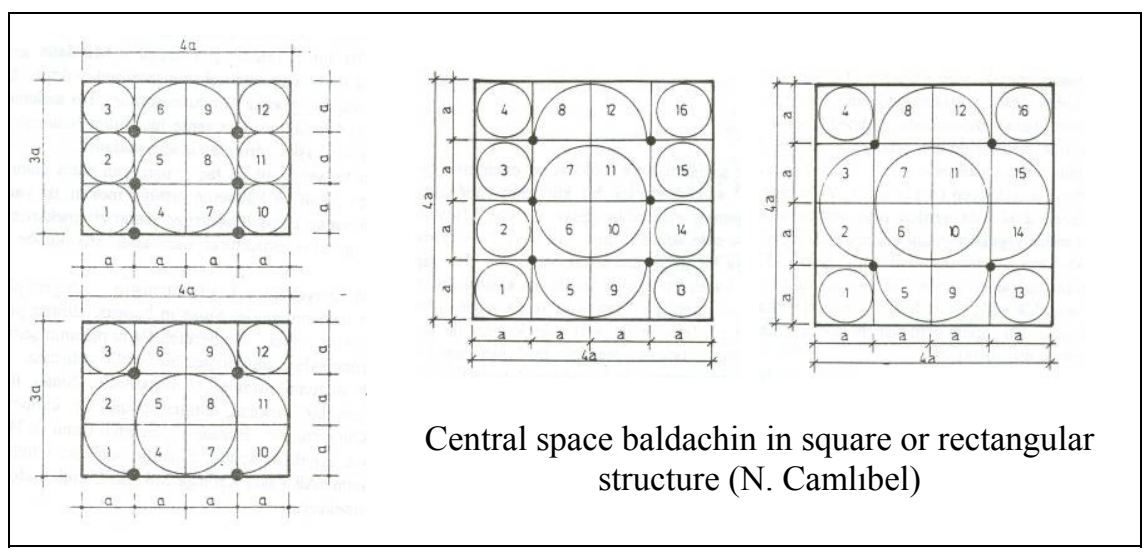

Figure 6: Baldachin and square or rectangular structure. 


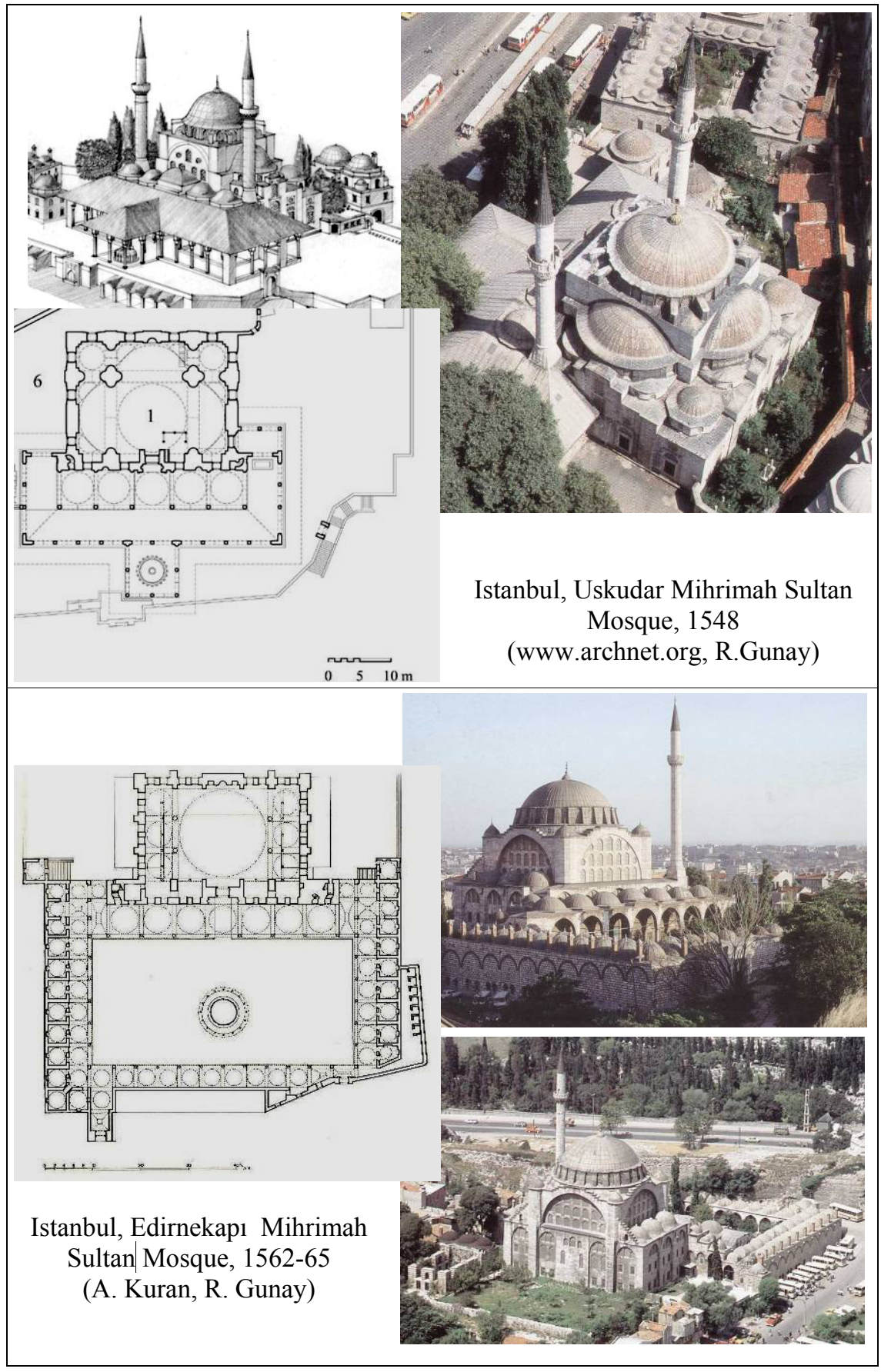

Figure 7: Sinan's mosques. 
158 Structural Studies, Repairs and Maintenance of Heritage Architecture XI

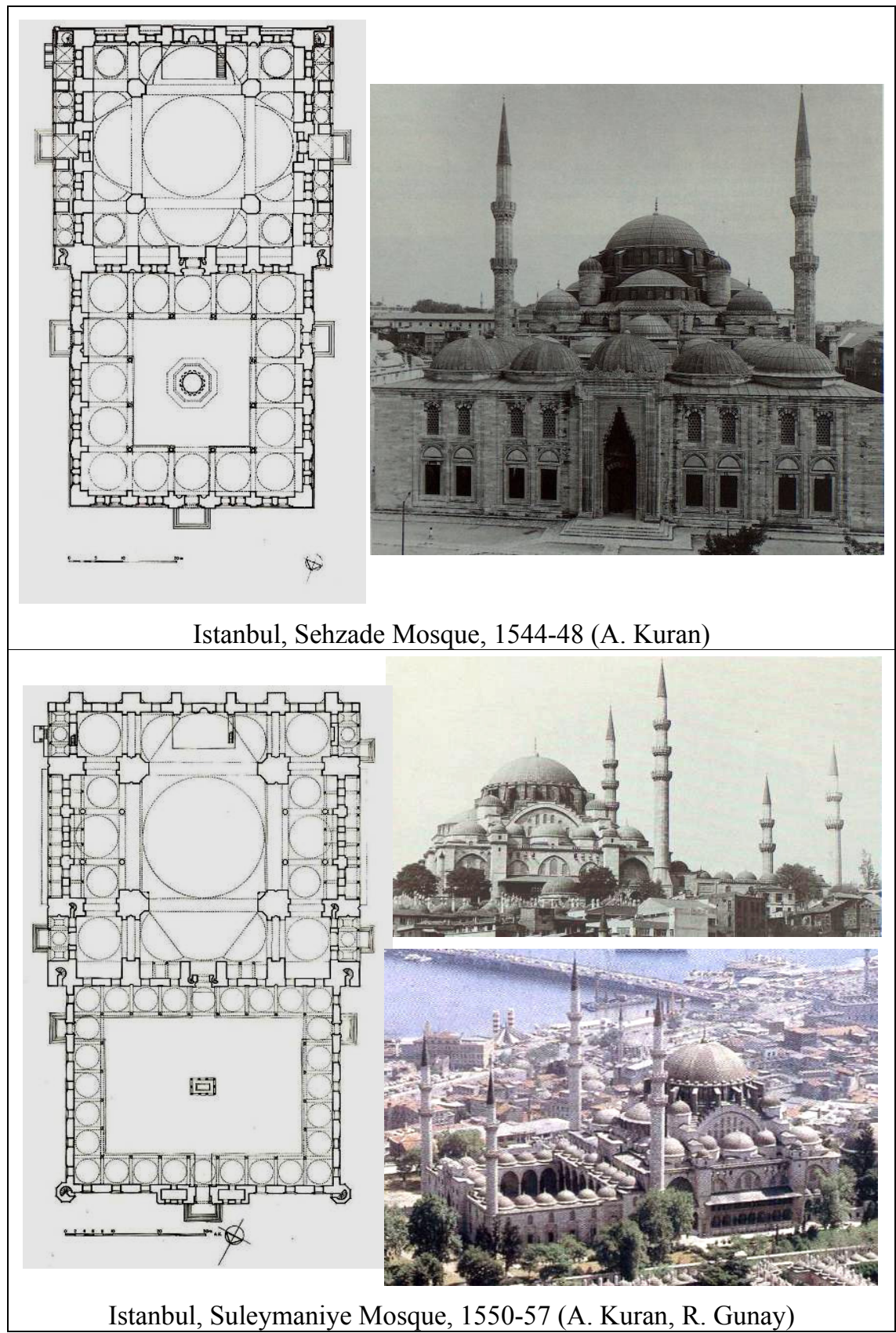

Figure 8: $\quad$ Sinan's mosques. 
This, at the same time is given different forms in the third dimension. The main dome or the central baldachin surprisingly becomes the focus of the design. For example, as in the Mihrimah Sultan Mosque in Istanbul, Uskudar, the central baldachin is projected over the main structure. This projection is exaggerated in the case of Mihrimah Sultan Mosque in Edirnekapı, Istanbul. Especially in this last example, in the facades of the main arches of the dome enabled by the advantages of the skeletal structure, the design incorporated several window openings.

\section{Evaluation}

In current building technology the skeletal structure is defined in a post and lintel system as the entirety of the structure. The reinforced concrete construction forms a monolithic character. In other words, the structural elements of the reinforced concrete building, such as the column, beam, slab, display a unified monolithic structure, whereas the steel construction has segmental character. Despite the reinforced concrete construction, here the structural elements like columns, beams and slabs carry a standardized prefabricated character. Nonetheless, the definition of skeletal character better goes along with the reinforced and steel construction. Due to its segmental character, the masonry construction composed of elements like brick, stone, mortar, cramps seems to imply more of a heaped construction definition. But the examples reveal that, like in reinforced concrete and steel construction, a structural system was used which can be denominated as the skeletal structure.

\section{References}

[1] Camlıbel, Nafiz, Sinan Mimarliginda Yapı Strukturunun Analitik Incelenmesi, YTU Yayınları, Istanbul, pp. 38-43, 1998.

[2] Alioglu, E. Fusun, Mardin, Sehir Dokusu ve Evler, Tarih Vakfi Yurt Yayınları, Kasım, Istanbul, p. 102-103, 2000.

[3] Kuban, Dogan, Osmanl Mimarisi, Yem Yayınları, Istanbul, pp. 257-259, 2007.

[4] Kuran, Abdullah, Mimar Sinan, Hurriyet Vakfi Yayınları, Istanbul, pp. 235246, 1986. 